\title{
Pragmatismo em Filosofia, Realismo em Direito e o Duplo Assalto à Economia Política Clássica: as bases do First Law and Economics Movement na Progressive Era Americana (1880-1930)
}

\begin{abstract}
Resumo: O presente ensaio visa discorrer sobre o chamado First Law and Economics Movement, vinculado à Progressive Era Americana, cuja concepção possibilitou uma ruptura paradigmática na prática jurídica dos Estados Unidos. Juristas e economistas se uniram para desvendar, por um lado, as posições nitidamente economicistas assumidas pela Suprema Corte Americana no início do século XX, fundadas na economia do laissez-faire e justificadas, contrário senso, como meramente formalistas; por outro, buscaram propor a interação de ambas as disciplinas (direito e economia) para potencializar a consideração dos aspectos histórico-sociais das decisões judiciais e, com isso, abrir vista à discussão acerca da possibilidade de se redefinir os fundamentos econômicos do bem-estar geral da sociedade. Nesse sentido, enaltece-se, por consequência, a existência de um movimento econômico do (ao) direito de cunho progressista e nitidamente anterior aquele iniciado na década de 60 do século XX pela University of Chicago.
\end{abstract}

Palavras-chave: First Law and Economics Movement. Progressive Era. Substantive Due Process.
Alfredo Copetti Neto ${ }^{1}$
Abstract: This essay aims to discuss the so-called First Law and Economics Movement, linked to the American Progressive Era, whose design allowed a paradigmatic rupture in the american legal practice. Lawyers and economists have joined together to unravel by one hand, the positions assumed by the distinctly economistic U.S. Supreme Court in the early twentieth century, based on laissez-faire and justified, contrary sense, as mere formalists; on the other hand, sought to propose interaction of both disciplines (law and economics) to enhance the consideration of historical and social aspects of judicial decisions and, therefore, open for the discussion of the possibility of redefining the economic fundamentals of the general welfare of society. In this sense, it welcomes, therefore, the existence of an economic movement of the law, linked with the progressists and clearly earlier from that started in the 60 s of the twentieth century by the University of Chicago.

Key words: First Law and Economics Movement. Progressive Era. Substantive Due Process.

1 Bolsista de Pós-doutorado (PDJ-CNPQ). Doutor em teoria do direito e da democracia pela Universitá degli Studi di Roma Tre. Mestre em direito público pela Universidade do Vale do Rio dos Sinos (Unisinos). Docente permanente do Programa de Pósgraduação em Direito da Unijuí. E-mail: alfredocopetti@yahoo.com.

Recebido em: 30/08/2012.

Revisado em: 10/09/2012.

Aprovado em: 09/10/2012. 


\section{Introdução}

Ao tratar-se do First Law and Economics Movement à época da Progressive Era americana, mostra-se imprescindível abarcar algumas questões preliminares.

Dentre os temas a serem considerados, frisa-se o método histórico, inicialmente desenvolvido na Universidade de Göttingen pela German Historical School - reverenciado pela American Institucionalist School -, cuja influência à compreensão do desenvolvimento da vida econômica moderna na sociedade americana foi de fundamental importância. Nesse sentido, levando-se em consideração a virada do século XIX ao século XX, buscou-se uma explicação mais adequada à complexa situação que evolvia a ideia de monopolização, fruto das nascentes indústrias das estradas de ferro - railroads. (HOVENKAMP, 1991, p. 131)

O exemplo privilegiado dessa empreitada continental em busca de uma reestruturação metodológica da economia americana, isto é, à parte das novidades importadas da política econômica britânica neoclássica, foi a fundação, em 1885, da AEA - American Economic Association -, instituição que levou ao fim e ao cabo a metodologia histórica alemã (HOVENKAMP, 1991, p. 299; HOVENKAMP, 2000), fazendo com que as pesquisas econômicas, antes fundadas em leis universais e imutáveis, navegassem nos mares da estatística e da história, com o intuito de responder mais satisfatoriamente às atuais condições da vida industrial que estava surgindo ${ }^{2}$.

Os principais expoentes desse desafio, sintetizado pela American Economic Association, Edwin R. A. Seligman e Henry Carter Ada$\mathrm{ms}$, foram aqueles que inauguraram, de forma expressa, o que se pode chamar de primeiro movimento da Law and Economics no continente americano (HOVENKAMP, 1990, p. 993-1.058). Clamando pelo diálogo teórico-prático entre a economia e as ciências sociais, eles busca-

\footnotetext{
2 É necessário referir que depois da década de 1930 do século XX, com a diminuição da visão institucionalista na economia, a American Economic Association, antes criada ao compasso do progressivismo, foi tomada por um forte pensamento conservador.
} 
ram trazer à tona uma espécie de hibridismo da barreira imposta pela microeconômica neoclássica para a ciência econômica - articulada sobre a premissa de que a economia era um sistema matemático, portanto, puro e dedutivo - para reconhecê-la, também, na intersecção da ética e da história. (HORWITZ, 1992, p. 182 e ss.)

Inclusive, mesmo com o reaparecimento da história como ciência - e não como método de interpretação -, de toda a forma, não se manteve à parte o interesse de históricos pelo método de interpretação econômica. O exemplo clássico dessa paradoxal expressão foi a incorporação de Charles Beard, um historiador, ao Departamento de Direito Público da Columbia University, o que prorrogou e fez verter novos ânimos à discussão em geral.

Beard, em sua mais influente obra, publicada pela primeira vez em 1913, cujo título An Economic Interpretation of the Constitution of the United States era o resumo daquele alento acadêmico, que surgira com o historicismo e que se fortalecera pelos pragmatistas e reformadores, direcionado ao estudo das forças econômicas e sociais para a compreensão dos problemas identificados com a realidade político-jurídica estadunidense. Ele defendia que a Constituição Norte-Americana era o exemplo do triunfo dos interesses materiais dos membros daquela convenção, ou seja, era o transplante do capitalismo para a América. (BEARD, 1986, p. 152 e ss.)

Muitos históricos, desse modo, valeram-se de teorias econômicas para explicar o desenvolvimento do direito. Identificar problemas sociais e formular políticas para resolvê-los mediante a legislação, as ordens do executivo ou as regras jurisdicionais era o campo em discussão. Tais afirmações tinham subjacente a elas o respaldo de uma (re)formulação científica, o que, de todo modo, as cobria de plausibilidade para que fossem cumpridas. 


\section{As Bases da Progressive Era Americana e o Debate Jurídico acerca da Doutrina do Substantive Due Process}

O surgimento da chamada Progressive Era se mostra como o pano de fundo desse contexto. Sob dois argumentos basilares, acadêmicos de direito e de economia montaram um assalto paralelo à política econômica do laissez-faire: por um lado, debruçaram suas críticas à falácia da proteção constitucional da esfera econômica da vida, no que diz respeito a um mercado moral espontâneo e autodefinido, edificado sob as vestes do regime proprietário e do direito contratual; por outro, em consideração a essas mesmas vestes, sob o aspecto da necessidade, mas também da dificuldade em promover a distribuição de riqueza pelas instituições da justiça. (FRIED, 2001, p. 3)

Nesse sentido, a preocupação intelectual dos reformistas sociais americanos, cuja época de atuação se compreendia entre os anos de 1880 até $1930^{3}$, defendia uma política intervensionista do Estado, cuja base afirmava que políticas públicas referentes à formulação de leis direcionadas para a proteção de um mínimo salarial, por exemplo, pelo seu empirismo, trariam um melhor uso dos recursos econômicos do que a doutrina fundada em uma ampla liberdade contratual. (HOVENKAMP, 1991, p. 172)

Fala-se aqui de uma nítida contraposição em relação ao tempo em que o Legal Formalism dominava totalmente o direito constitucional dos Estados Unidos e com ele a doutrina do Substantive Due Process, elaborada pela incorporação ao texto constitucional americano em 1868 do 14th Amendment, que dispunha sobre a garantia de direitos civis. (NELSON, 1998)

3 Hovenkamp precisa este período entre 1871 - data em que Charles Darwin publica a obra The Descent of Man e vincula a espécie humana à teoria da evolução - e 1960 - data em que Ronald Coase publica o texto The Problem of Social Cost, revigorando a ideia de mercado não regulado. De toda forma, o autor reconhece o paulatino distanciamento ocorrido entre as disciplinas - direito e economia - que acontece entre os anos de 1930 e 1960, sobretudo pela influência de Lionel Robbins no marginalismo econômico. 
Teoricamente, a implementação do Substantive Due Process, do qual falava a nova emenda, vinha para corroborar a determinação feita pelo 13th Amendment, que três anos antes estabelecera a abolição da escravidão (ACKERMAN, 2006). Era necessário, após o término da guerra civil, dispor aos negros americanos as mesmas proteções constitucionais das quais gozavam os brancos. As pessoas nascidas nos Estados Unidos, naquele sentido, assumiram o status de cidadãs, e todos os cidadãos, sem preconceito em relação à raça, à cor e à condição social encontravam-se sob o resguardo dos mesmos direitos. (HOVENKAMP, 1991, p. 93)

Entretanto, a interpretação conservadora dada pela Suprema Corte - amplamente baseada no Legal Formalism, isto é, no pressuposto jurídico fornecido pelo pensamento de Cristopher Columbus Langdell (GREY, 1983, p. 5), e na política econômica do Laissez-Faire (DUXBURY, 1997, p. 9 e ss.) - fez com que se desvirtuassem os rumos do novo dispositivo constitucional ao entendimento de que ele havia sido criado para proteger substancialmente a liberdade de contrato.

É bem verdade, e por isso se mostra imprescindível referir, que as bases do formalismo legal tiveram emersões diversas (DUXBURY, 1997, p. 11): enquanto a ciência do direito de Langdell era fruto de uma força acadêmica desenvolvida na Harward Law School que buscava resolver a crise do direito americano promovendo a ideia de que o direito era uma ciência demonstrável por critérios lógicos, cujo enlace propriamente jurídico estaria no estudo do case method of legal instruction; a fé na política econômica do laissez-faire se desenvolveu juridicamente dentro da própria corte, sob a fundamental premissa de que o individualismo era moral e economicamente ideal. Não se pode olvidar, porém, a relação ideológica conservadora que virtuosamente se expandiu entre ambas as faces do formalismo jurídico americano. (GILMORE, 1991, p. 60-61)

Nesse sentido, a ignorância em relação ao tema de justiça racial e o favorecimento à economia de mercado, ou melhor dizendo, às liberdades econômicas individuais foi a interpretação dada pela Corte Suprema à nova emenda constitucional, restringindo, assim, o espaço de compreensão e contrariando os pressupostos históricos dos quais se valeram os parlamentares para a redação da nova emenda. 
Segundo Willian Nelson (1998, p. 11), um dos grandes estudiosos a respeito do dispositivo, o 14th Amendment assumiu, posteriormente, uma nova amplitude, mas concomitantemente uma restrição, cujas propostas iniciais não contemplavam. Tanto a Corte Suprema quanto os comentadores que analisaram posteriormente a emenda deixaram de reconhecer o significante avanço social ali contido, mas, ao mesmo tempo, os limites jurídicos destinados ao próprio poder judiciário de adentrar na esfera dos poderes legislativos.

De todo modo, a proposta de emenda à constituição tinha duas bases nítidas, capitaneadas, por um lado, pela proteção de direitos; por outro, pela garantia de que as legislações dos Estados-Membros estariam livres para adotar leis em benefício do bem-estar público. Ambas as teses abraçavam a discussão político-jurídica da época: "[...] to reaffirm the law public's longstanding rhetorical commitment to general principles of equality, individual rights, and local self-rule.” (NELSON, 1998, p. 8)

Duas paradigmáticas decisões, entretanto, acabaram por evidenciar a manutenção do status quo em relação à proteção dos direitos civis e, em algum grau, a redirecionar o 14th amendment em conformidade ao consenso conservador, cujo entendimento à real importância do dispositivo era a de constitucionalizar uma particular política econômica. (HOVENKAMP, 1991, p. 95)

Dito de outro modo, Francis Wharthon, Thomas Cooley, John Pomeroy, Christopher Tiedeman, etc., vistos como os grandes constitucionalistas da época, entenderam que com a promulgação do 14th Amendment os juízes foram convidados a adotar em suas decisões uma determinada teoria econômica, que visava à otimização estrutural das relações de mercado. Segundo eles, o problema dos afro-americanos estava resolvido com a simples proteção do acesso deles ao mercado, porém, a real proposta da emenda estava apenas começando a surtir efeito prático: “[...] enabel the courts to define individual economic liberties against the states." (HOVENKAMP, 1991, p. 96)

Obviamente que o descompasso ocorreu em relação à doutrina do Substantive Due Process of Law, formulada pela Suprema Corte, e referente à política legislativa incorporada ao texto constitucional pelo 14 th 
Amendment, como bem expressou o juiz Holmes, voto vencido no paradigmático Caso Lochner,

[...] the Fourtheenth Amendment does not enact Mr. Herbert Spenser's Social Statics... a constitution is not intended to embody a particular economic theory [...] (LOCHNER versus NEW YORK, 1905)

É possível afirmar que a $14^{\circ}$ Emenda da Constituição Americana, portanto, tinha o condão de proteger tanto os interesses das classes menos favorecidas, quanto a liberdade legislativa em prol do bem comum, entretanto, a corte constitucional restringiu sua interpretação à proteção dos interesses da classe proprietária, entendendo direitos civis como direitos meramente econômicos, vinculados à igualdade de acesso ao mercado.

A premissa classicista que definia que o governo não poderia escolher favoritos se tornou obsoleta para a proteção dos menos favorecidos frente às vontades corporacionistas do final do século XIX e início do século XX. Porém, faz-se imprescindível referir que na era do presidente Andrew Jackson (NELSON, 1998, p. 15 e ss.), que foi o marco inicial dessa proposta, a não preferência de interesses por parte dos poderes públicos centrava-se numa política voltada para as concepções esquerdistas, contrárias, portanto, para a proposta conservadora dos Federalistas. (BEARD, 1986; ACKERMAN, 2006)

Naquele contexto, a liberdade de contrato se colocava como um direito econômico, mas somente porque era compreendida e fundamentada por um direito moral e religioso, isto é, a ideologia do Laissez-Faire era composta tanto por uma ideia moral de autodeterminação quanto por uma visão de individualismo religioso, cujo fundamento remontava ao realismo escocês de Adam Smith. (HOVENKAMP, 1991, p. 74)

A liberdade de contrato, para Smith, provinha muito mais de um preceito moral do que de uma compreensão econômica propriamente dita; uma teoria do homem econômico somente seria possível de ser aceita quando fosse interpenetrada por uma teoria do homem moral, que por sua vez abarcava a concepção lockeana de que cada pessoa tinha o direito natural ao seu próprio trabalho, cujo valor seria, por isso, a função do 
trabalho colocado em algo, determinado pelo mercado e sempre normativamente correto.

Tal concepção somente foi perdendo força no início do século XX, quando o utilitarismo - em competição com a ortodoxia protestante - fortaleceu-se sob o argumento pragmático de que uma moral ateísta baseada na maximização da satisfação humana traria maior proteção democrática às decisões públicas. (HOVENKAMP, 1991, p. 68)

$\mathrm{Na}$ verdade, a concepção de liberdade negativa - por meio da qual, de forma deficitária, se fundamentou a corrente ultraindividualista do estado mínimo, promovida por Herbert Spenser (1981), cuja obra The Man versus The State era amplamente conhecida na América do Norte - não deixou de contemplar a concepção promovida pelos progressistas, tampouco de se vincular às obras dos grandes precursores ingleses desse pensamento. Para Stuart Mill e Henry Sidgwick, por exemplo, as legislações progressistas, como parte, inclusive, da proposta de expansão da atuação do estado na economia, paradoxalmente, viriam a salvaguardar, justamente, a ideia de liberdade, ou seja, a segurança de um mínimo social estaria contida no individualismo. (MILL, 2011; FRIED, 2001)

De todo o modo, a tradição constitucionalista do Due Process desenvolvida pela Corte Suprema americana, mais do que uma doutrina puramente jurídica - um sistema formal de direitos - era calcada em uma específica teoria econômica - aquela clássica de Smith, aplicada, porém, num outro contexto -, e que em alguma medida vinha fortalecida e redirecionada pela já amplamente difundida ideia de Darwinismo Social.

Contra as formulações da Suprema Corte Americana, que àquela época fora batizada de Corte Lochner, em relação ao seu tríplice fundamento - formalismo lógico langdelliano, teoria econômica clássica e darwinismo social -, foi que se voltaram às posições de toda a Progressive $\mathrm{Era}^{4}$, compreendida no movimento do Realismo Jurídico em compasso com a Economia Institucionalista e os primeiros marginalistas, sob a base situada na Filosofia Pragmática ligada a John Dewey, William James e

4 Não se pode deixar de referir que o grupo dos reform darwinists, em conformidade com a marginalist revolution do início do século XX, tiveram um importante papel na Progressive Era. 
Charles Sanders Peirce, cujas afirmações a respeito de que o conhecimento e o pensamento humano se desenvolvem dentro das relações socioculturais, fornecia o aparato teórico para contrastar os argumentos abstratos e formalistas, dos quais a corte se valia para se abster da assimetria da realidade social. (DUXBURY, 1997, p. 35)

As reivindicações formalistas de objetividade jurídica pelas quais se sustentavam as decisões da Corte Americana serviam, somente, para evidenciar uma seleta teoria econômica, que, em algum grau, pertencia muito mais aos juízes do que aos legisladores. (HOVENKAMP, 1991, p. 172 e ss.)

Nesse sentido, embora a falta de linearidade e, até mesmo, a paradoxalidade atribuída aos progressistas, mais especificamente à corrente realista (HORWITZ, 1992, p. 169), ela serviu para pôr em evidência e para defender a concepção de que o debate jurídico tinha, necessariamente, uma vertente ideológica, com posições políticas, econômicas e morais claras, que deveriam ser, em primeiro lugar, aceitas abertamente e, depois, discutidas.

\section{A Corrente Reformista: o duplo caminho tomado pelo Realis- mo Jurídico}

Contra a arquitetura erguida pelos Classical Legal Thinkers, no sentido em que o direito como ciência (GREY, 1983, p. 5; GILMORE, 1991, p. 44) não poderia refletir ideias externas pelo fato de pôr em risco o título de ciência, mas também contra uma mesma premissa ultraindividualista que pressupunha a ampla regulação coercitiva da esfera pública e a não regulação coercitiva da esfera privada, foi que Oliver Wendel Holmes Junior (1992, p. 166 e ss.) pôs em voga a discussão lógica versus experiência/abstrato versus concreto para desvendar a amplitude da ideologia conservadora que estava por detrás daqueles argumentos e, com isso, reconhecer que a abstração formal não dava conta, sozinha, de resolver os conflitos heterogêneos e competitivos, impostos pela era das corporations à sociedade americana. (GILMORE, 1991, p. 62) 
O formalismo jurídico, assim, assumira, em alguma medida, um lugar secundário sob o ponto de vista inicial do pensamento realista ${ }^{5}$. Teoricamente isso quer dizer que ele não impunha a desigualdade de riqueza e de disparidade de poder pelo fato de trazer consigo pressupostos lógicos e neutrais desenvolvidos a priori, ele somente os aceitara pelo fato de ser uma teoria objetiva - descritiva -, acreditando, obviamente, que aqueles fatos eram contingentemente impostos, como situações naturais pré-políticas - verdadeiras -, que não caberia ao direito qualquer alteração. (GREY, 1983, p. 6)

Não obstante tudo isso, foi em função de uma definição objetiva e abstrata de livre contrato e, consequentemente, de liberdade, que os juízes americanos acabaram por edificar o inteiro corpus do direito contratual, ou melhor, do inteiro corpo constitucional estadunidense, na medida em que resumiram este àquele, reconhecendo toda e qualquer restrição estatal para a liberdade contratual como uma privação da própria liberdade constitucional, cuja repercussão, volitiva ou não, andava ao encontro de uma específica teoria econômica, por coincidência, isso sim, erguida sob as mesmas arestas teóricas, de clareza natural, certeza e objetividade, tal qual se determinava àquela jurídica. (MINDA, 2001, p. 51)

Sob o enfoque argumentativo progressista, de todo modo, a dedução de conceitos lógicos formais dos quais se valiam os juízes da Suprema Corte Americana era somente o pano de fundo para não serem citados expressamente modelos consensuais desenvolvidos por outras disciplinas, tendo em vista que os atos legislativos pelos quais passavam como estatutos as políticas estatais ao redimensionamento econômico feito por via artificial, na maioria das vezes, não continha nenhum vício à declaração de inconstitucionalidade, mas se mostrava taxativamente contra a própria política do Due Process desenvolvida pela corte, que acreditava ser economicamente irracional, ser passível de corrupção e aberto a pri-

5 É necessário atentar que o protorrealismo de Holmes não era totalmente contra o formalismo de Langdell. Sua luta, verdadeiramente, era contra o abuso de princípios abstratos. Gilmore sustenta, ironicamente, a afirmação de que os realistas jurídicos quiseram abandonar a teoria langadelliana tal como os reformadores protestantes dos séculos XV e XVI quiseram abandonar os dogmas da teoria cristã. 
vilégios especiais qualquer transferimento involuntário de riqueza. (HOVENKAMP, 1991, p. 181-182)

A crítica posta em voga por Holmes - que nas palavras de Grant Gilmore forneceu conteúdo à metedologia langdelliana (GILMORE, 1991, p. 48) - encontrou ecos sob um viés doutrinário pragmático em Roscoe Pound (1909) 6 , para quem a liberdade contratual era vista como uma falácia argumentativa e se justificava pelo fato de as cortes americanas terem perdido o contato com o mundo da vida ${ }^{7}$.

Pound afrontou duramente a abstração filosófica, segundo ele de base apriorística kantiana, da qual se valia a corte para decidir casos concretos. A sua celebre colocação Law in books and Law in action (POUND, 1910, p. 12) era o resultado dessa abstração e o conteúdo daquilo que ele chamou de Mechanical Jurisprudence (POUND, 1908, p. 605). O reflexo dessa posição pôs em destaque a discussão até então latente no direito americano: como seria possível a ciência jurídica americana, num sentido amplo, reger a dicotomia individualismo-socialismo?

Tal colocação, pode-se dizer, fez nascer um vasto debate acadêmico que tomou conta não somente da prática jurídica, senão também dos argumentos políticos e econômicos. Os holofotes voltaram-se para a ideia de que a lei deveria entrar em jogo para suprir a inabilidade dos tribunais em lidar com as situações complexas que paulatinamente vinham surgindo. A crença estava voltada agora à via legislativa, meio apto para projetar e garantir as mudanças das quais necessitava a sociedade americana. (GILMORE, 1991, p. 18)

6 Não faltam argumentos (MINDA, 2001; DUXBURY, 1997), porém, que classificam Pound, no final de sua carreira, como um reacionário extremado, tendo em vista suas declarações em favor do regime nazista.

7 Mostra-se importante salientar também a grande influência exercida por Louis Dembitz Brandeis no movimento realista, sobretudo e especificamente pela sua excepcional pesquisa empírico-sociológica sobre os malefícios à saúde da mulher proveniente do excesso de horas diárias trabalhadas. Brandeis - que para alguns foi mais influente aos pensamentos de Holmes do que influenciado por eles - submeteu à Suprema Corte tal pesquisa, visando a defender a constitucionalidade de uma lei proposta pelo Estado do Oregon, que disciplinava em dez horas o limite de trabalho das mulheres. (STHUM, 1984) 
Sob a ótica dos realistas, especialmente Pound, a práxis jurídica era contingentemente impregnada pela práxis social. As decisões judiciais traziam claras consequências socioeconômicas e diziam muito a respeito da posição política dos juízes (DUXBURY, 1997, p. 58). A luta de Pound, nesse sentido, tinha como meta alçar o pragmatismo ao mesmo patamar em que se encontrava a abstração formalista para que fosse possível o enraizamento de sua Sociological Jurisprudence (POUND, 1910, p. 610), cujos fundamentos se voltavam, por um lado, à limitação do arbítrio judicial pela lei; por outro, à consideração das últimas coisas, dos fatos, nas próprias tomadas de decisões, isto é, daquelas consequências socioeconômicas.

No lugar da máxima formalista de que o direito é uma ciência, os progressistas rediscutiram as premissas básicas dessa afirmação para, sob um outro prisma - mas não sob uma outra meta -, pleno de significados e redimensionamentos, declarar que o direito é uma ciência social (GILMORE, 1991, p. 83) e que, justamente por isso, não se encontrava imune às perspectivas de um ponto de vista sociológico, ou melhor, não era outra coisa senão uma disciplina integrada às ciências sociais, como a sociologia e a economia. (GILMORE, 1991, p. 83)

Em face disso, os progressistas, não longe dos sociais reformistas ingleses, reconduziram a premissa inicial da seguinte forma: "[...] laws of Production and Distribution, and some of the practical consequences deducible from them [...]" (MILL, 2001, p. 15) são de fundamental importância e devem ser levadas em consideração, pois fazem parte do próprio sistema jurídico. Aliás, não somente dele, mas de todo o poder político que, precedentemente à Primeira Guerra Mundial, acreditava numa espécie de intervenção governativa, cujo fim se direcionava a um suposto melhoramento da qualidade de vida da população.

Relacionada a isso estava a criação moderna do Estado Fiscal Americano, ou seja, uma proposta de política econômica direcionada por uma política tributária, predominantemente pluralista e democrática, que visava a mudar o status da regulamentação das cobranças acerca da utilidade pública. (FRIED, 2001, p. 6) 
Nesse sentido, o ataque à Suprema Corte em particular, e, em alguma medida, ao papel da esfera pública em geral, tinha por base a implicação de que a obrigação governamental era a de maximizar o bem-estar coletivo e de melhorar as condições dos cidadãos, sobrepondo-se, inclusive, à proteção dos direitos individuais. Sob a base pragmatista reformadora, o argumento invocado pelos progressistas tinha em vista remodelar cientificamente a consciência das decisões governamentais, com premissas calcadas no empirismo e em direção à necessidade de um reajuste quanto às garantias de um mínimo social a todos os cidadãos. (FRIED, 2001, p. 6)

Noutras palavras, as duas pontuais formulações do liberalismo clássico invocadas pelos juízes superiores - liberdade de interesses e direitos de propriedade - seguiam a direção às críticas dos progressistas. Em face disso, mas especialmente pela tentativa de ruptura com o paradigma clássico que, segundo os progressistas, era o responsável por esse entendimento, formularam-se os ataques partindo de âmbitos diversos: a) quanto ao critério científico, em relação aos quesitos de pureza lógica do direito; b) quanto à questão da dicotomia público/privado, em relação ao seu papel coercitivo público, voltado ao direito tributário, penal, constitucional e regulatório; em relação ao seu papel não coercitivo privado, que abrangia os direitos contratuais, responsabilidade civil e direito comercial. (HOVENKAMP, 2011)

Enquanto para os clássicos a cientificidade jurídica se dava pela pureza das preposições abstratas que seriam construídas a priori e direcionadas aos casos concretos, cuja aplicação era voltada tão somente ao direito privado à proteção da esfera individual contra o próprio poder do estado; o direito público, sobretudo o direito constitucional, era amplamente reconhecido como não científico, contaminado, desse modo, por concepções políticas e morais impuras.

\subsection{A Face Progressista do Realismo Jurídico}

Para os progressistas/realistas, as duas célebres frases cunhadas por Holmes - "The life of the law has not been logic: it has been experience" (HOLMES JUNIOR, 1991, p. 1) e "General propositions do not decide concrete cases” (HOLMES JÚNIOR, 1992, p. 306) - diziam muito e tra- 
ziam a resposta, ou, ao menos, o meio mais apto para indagar acerca das formulações ortodoxas das quais se valiam os clássicos para estabelecer toda a estrutura jurídica americana.

Isso quer dizer que o realismo, nesta vertente progressista, mostrou-se reformador e privilegiou a experiência em detrimento da lógica. Formada pelos insights dos cientistas sociais e pela clareza da estatística que os dados empíricos possibilitavam - nitidamente a influência de Pound e Brandeis se faz valer -, o braço reformista do realismo afrontou o caráter lógico do direito, sem com isso eliminá-lo. (MINDA, 2001, p. 57)

A lógica foi posta como subalterna à experiência; o ser da realidade se sobrepôs ao dever ser da regra (LLEWELLYN, 2008); o direito tinha de estar, verdadeiramente, livre de valores, tinha de ser descritivo, avalutativo, tinha de operar no âmbito prático diante das políticas por ele próprio perseguidas; o procedimento, em relação à substância, respondia com mais clareza ao pedido ascético, apolítico do direito visto como ciência social.

O conceitualismo jurídico de Langdell, para tanto, foi substituído pelo conceitualismo sociológico dos realistas progressistas, o que, consequentemente, pôs em evidência o método científico empírico, cuja sólida base pragmática ajudou a sintetizar conceitos a posteriori em que as ciências sociais, sobretudo a economia, assumiam relevante papel às análises jurídicas, oferecendo sistematização e autenticidade, tanto nas resoluções de problemas concretos, quanto na produção de políticas jurídicas à tutela e à reformulação da concepção de interesse público. (GILMORE, 2001)

The life of the law has not been logic: it has been experience era o paradigma que fundava o viés progressista da corrente realista. Na busca da previsão fática do comportamento jurídico, desse ou daquele caso, os progressistas sustentavam a tese positivista da separação entre direito e moral/política pela libertação valorativa do direito, limitando suas análises a meras descrições de situações factuais em que o juiz poderia decidir dessa ou daquela forma. 


\subsection{A Face Radical do Realismo Jurídico}

Entretanto, a outra face do realismo, a chamada ala radical ou critica do movimento, arraigou-se na exploração da dicotomia abstrato versus concreto. Enfatizando o aspecto normativo do direito, os radicais apontaram para a discussão de que o direito é, foi e sempre será um dever político e moral.

Desse modo, foram eles, os críticos, que atentaram mais fortemente para a descoberta da falácia argumentativa estabelecida pela dicotomia público/privado do pensamento clássico. O equívoco descoberto por essa face do realismo tinha a ver com a pretensão individualista - possessiva (MACPHPERSON , 1979) - e, de certa forma, ardilosa de fundar o direito privado em premissas naturais (pré)apolíticas, ofuscando o caráter eminentemente convencional e ideologicamente conservador no qual se baseava o discurso jurídico-político.

O próprio poder político estatal - acompanhado e influenciado pelo poder econômico e, justamente, político -, declararam os realistas radicais, foi o responsável pela criação e pela articulação da naturalidade do direito privado e, consequentemente, pela imunização de uma possível normatização jurídica performática do seu âmbito de atuação, isto é, da esfera privada, em direção da distribuição da riqueza. (FRIED, 2001, p. 10)

O enfoque dado ao caráter objetivo das categorias formalistas acabou por afirmar que muitas das classes fundamentais da doutrina jurídica eram incoerentes e que a base do silogismo formal lógico empregado pela Corte Suprema para a resolução de casos concretos somente evidenciava juízos eminentemente políticos acerca do papel do direito na sociedade. Para que fosse possível a plena justificação das ações dos tribunais, refere Felix Cohen (1935, p. 809-810), mostrava-se imprescindível buscá-las fora dos termos jurídicos específicos.

\subsubsection{Robert Hale e a Perspectiva Reformadora do First Law and Economics Movement}

Grande exemplo e, talvez, a síntese mais expressa dessa parte do movimento realista foi Robert Hale (1935, p. 149 e ss.; 1923, p. 470 e ss.), 
na medida em que aglutinou em si o mais nobre pensamento da Economia Institucionalista e do Realismo Jurídico, isto é, voltou-se a entender os fundamentos legais do mercado e a relação existente desse fundamento com as instituições sociais que condicionam a vida econômica. (FRIED, 2001, p. 3)

Formado em ambas as áreas - direito e economia -, Hale centralizou seus ensinamentos acadêmicos com o intuito de preparar advogados, juízes e economistas para a compreensão de que o direito contratual americano servia, basicamente, e, sobretudo, para justificar o seu intrínseco poder coercitivo, em que o ideal afirmado de liberdade contratual estava sistematizado por uma lógica racionalizada, voltada à manutenção da desigualdade social. (FRIED, 2001, p. 3)

O direito entendido como um mecanismo eficaz ao controle social - termo cunhado por Ross, mas trazido à seara jurídica, pode-se dizer, com Llewellyn, pela engenharia social de Pound - foi assim reconhecido e tratado pioneiramente na Columbia University. Hale, diante dessa característica funcional, levou ao fim e ao cabo tal perspectiva, enaltecendo expressamente o estudo dos aspectos econômicos envolvendo o direito, bem como a ideia de limitação constitucional, até então tratada - erguida - pelos formalistas como uma espécie de impedimento de revisão por parte do estado em relação à tese santificada como direito de propriedade. (FRIED, 2001, p. 19)

Se o debate envolvia questões valorativas e relações de poder, em que o aspecto ideológico se refletia das mais variadas formas, nada mais distintamente honesto do que reconhecer tais assertivas e trazer aos programas universitários, ao debate jurídico-acadêmico, linhas de discussões voltadas à filosofia, aos negócios, às ciências sociais - especialmente à economia - e à ciência política, na medida em que somente desse modo o direito estaria apto para afrontar as relações secretas de poder que se desenvolviam contextualmente na sociedade. (MINDA, 2001, p. 55)

$\mathrm{Na}$ verdade, se o realismo dos progressistas era uma espécie de reformulação do conceitualismo langdelliano; o realismo dos radicais, ou crítico, por outro lado, era a sua negação, a sua antítese, justamente porque descobria e afrontava de forma direta o caráter ideológico-político 
que se maculava como lógica jurídica racionalizada, fundante do pensamento conceitualista clássico.

A pureza e a descrição científicas eram as distorções conceituais que vinham ferrenhamente combatidas pelos críticos. O des(en)cobrimento do poder por detrás da liberdade fez surtir a base para o alargamento da discussão acerca das opções e dos fundamentos políticos que desencadearam, sobretudo constitucionalmente, a ideia de que somente o poder público exerce coerção à liberdade privada. (FRIED, 2001, p. 17)

Com efeito, o perspicaz argumento apresentado por Hale caracterizou como erro a concepção comumente aceita de que a coerção seria um ato compulsório do poder público que privaria qualquer indivíduo de possibilidades de escolha. Pelo contrário, segundo ele, a coerção assumiu uma forma indeterminada e indeterminável, cuja capacidade não foi somente de impor taxativamente, mas também, e tratando-se de questões como a liberdade e a propriedade, ou melhor dizendo, questões referentes à liberdade contratual como síntese disso, sobretudo, de constranger e de limitar a avaliação de alternativas de escolha em que o ser humano seria, justamente, livre para escolher. (HALE, 1939, p. 470 e ss.)

Evidentemente, a coerção se fazia presente na esfera privada, talvez de modo indistinguível daquele exercido pelo poder governamental, porém tradicionalmente camuflada como liberdade de ação, protegida e possibilitada - (da) pela coerção estatal - sob a forma de um sistema criado, acredita-se, justamente para fortalecer não a liberdade na sociedade em seu aspecto empírico, mas, especialmente para, de modo abstrato, enrijecer a premissa colocada como liberdade contratual.

A desmistificação de que o mercado era natural, pré-político e neutro foi trabalhada por Hale, como se pode notar, em três distintas, mas vinculadas, concepções: a) sob o aspecto da artificialidade do direito natural de propriedade; b) sob o aspecto da coerção, exercida não somente pela esfera pública, mas também pela esfera privada; c) sob o aspecto do papel do direito na estruturação da vida econômica da sociedade.

$\mathrm{Na}$ verdade, o que Hale fez foi desmistificar o ethos do livre mercado, na medida em que reconheceu a relação inversamente proporcional 
ditada pelo poder de barganha à suscetibilidade da coerção econômica, ou seja, a liberdade econômica tinha o caráter preponderante de força econômica e, desse modo, quanto mais forte economicamente se mostrava um sujeito, mais livre empiricamente ele se tornava.

Em específico, a redefinição proposta por Hale sobre o aspecto da coerção foi de fundamental importância para a construção de uma inédita e característica, ao menos no paradigma americano, teoria da regulação, haja vista que promoveu pontos argumentativos irrefutáveis que fortaleceram e entusiasmaram as pesquisas daqueles acadêmicos engajados, por um lado, em limitar as abstrações do conceito de liberdade contratual; por outro, em expandir, sob os aspectos pragmático e funcional, esse próprio conceito. (HALE, 1939, p. 563-594)

Nesses termos, a coerção assumiu três diferentes vieses ao seu entendimento, dois característicos da sua estrutura e um consequencialista, isto é, se levados em consideração os anteriores: em primeiro lugar, ela deve ser atendida como condição inexorável, que se manifesta em todas as esferas onde exista a dicotomia poder-liberdade e, além disso, diante dessa dicotomia, mostra-se, por essas esferas, essencialmente desejável; em segundo lugar, a coerção é derivada de diferentes substratos, ou seja, necessidades naturais, condições legais impostas, direta ou indiretamente, por meio dos institutos da propriedade ou do contrato, os quais estão a cargo da própria esfera pública; em terceiro lugar, sendo considerados ambos os enfoques mencionados - o seu caráter inevitável e a sua plural derivação - mostra-se como inadequada a censura prévia, sobretudo se jurisdicional, à implementação de políticas públicas intervencionistas promovidas pelo Estado, ainda que dela surtam efeitos diretos nas escolhas privadas, sob o argumento meramente factual de que se trata, lato sensu, de coerção.

Assim, fez-se necessário reconhecer, mesmo que minimamente, a inexorabilidade de uma política pública normativa, determinada de forma democrática pela sociedade, que fosse especificada e deliberada tanto quanto às suas formas, como ao seu ângulo e a sua intensidade de - redistribuição da - coerção. 
Entretanto, em que pese a possibilidade de um desajuste conceptivo em relação ao grau da coerção, no sentido da redistribuição do poder de barganha, as posições que pregavam a manutenção do paradigma clássico, cujo fundamento se enquadrava na ideia de que nenhuma hipótese de intervenção pública era permitida nos atos - coercitivos dos poderes de barganha - privados, seriam caracterizadas, não mais como relacionadas diretamente a direitos naturais, mas sim como uma exacerbada proteção de atos cuja vedação total à intervenção pública era fruto da própria política estatal e se caracterizava, pela crítica promovida por Hale, pelo ponto de vista de uma vedação convencionada institucionalmente e, de certo modo, incompatível com qualquer teoria minimamente coerente da liberdade.

\section{A Consolidação do First Law and Economics Movement e a Revolução Marginalista objetivista: notas esclarecedoras em comparação ao marginalismo subjetivista de Lionel Robbins}

A compreensão do pensamento da Era Progressista fazia jus às palavras de Peirce no ensaio intitulado How to Make Our Ideas Clear:

A clear idea is defined as one which is so apprehended that it will be recognized wherever it is met with, and so that no other will be mistaken for it. If it fails of this clearness, it is said to be obscure. (PEIRCE, 1878, p. 286)

Era óbvia a crença de que as instituições estavam envolvidas em todos os aspectos, seja naqueles voltados à tomada de decisões da esfera pública, seja naqueles voltados à esfera privada. O curso da evolução, tendo por base o pensamento de Charles Darwin (1998) passava necessariamente pela deliberação humana, assim, não existia nenhum motivo para se privilegiar o status quo em detrimento do que se poderia produzir pelas instituições legais por meio de uma política legislativa progressista, para a necessária motivação da redistribuição da riqueza. 
Tornar a esfera pública uma força positiva na economia, na medida em que inevitavelmente constitutiva da vida econômica, fazia convergir, em algum grau, o pensamento progressista britânico dos teóricos de esquerda, que se valiam de certos insights da Revolução Marginalista do final do século XIX, bem como de uma gama de novos liberais - não caracterizados como liberistas ${ }^{8}-$ do início do século $\mathrm{XX}$, para compor o argumento de que era necessário controlar os lucros desproporcionais que os produtores realizavam, por meio de políticas de controle de preços e de taxações, tendo em vista a necessidade de financiamento do bem-estar geral.

A reforma social que se construía pela regulação econômica vinha articulada não somente pela segunda premissa colocada por Holmes General propositions do not decide concrete cases -, mas também pela crença de que o valor econômico era um conceito social, mais do que individual e, por isso, tinha um papel fundamental para a compreensão das necessidades da população.

$\mathrm{O}$ interesse daquilo que nitidamente se caracterizava como o First Law and Economics Movement nos Estado Unidos, tendo em vista a explícita aglutinação de ambas as disciplinas ${ }^{9}$, voltou-se para a ideia de que

8 O novo liberalismo era um movimento progressista, iniciado na virada do século XIX para o século XX. Era também conhecido como liberalismo radical ou liberalismo social e se postava, sob o aspecto político, à esquerda do liberalismo clássico. Alguns nomes vêm à tona para sintetizá-lo, como, por exemplo: Leonard Hobhouse na Inglaterra, Franz Oppenheimer na Alemanha e John Dewey na América do Norte. É possível afirmar que o novo liberalismo está à base do considerado primeiro movimento Law and Economics. Importante salientar, contudo, a extrema diferença e, até mesmo, a pioneira autenticidade e profundidade desse pensamento em relação ao segundo movimento Law and Economics que, não bastando a reutilização do nome para outros fins, valeu-se, como não poderia deixar de ser, do chamado neoliberalismo ou liberismo econômico, cristalizado em Friedrich von Hayek - que, coincidentemente, também restabeleceu o nome do movimento anterior, para se colocar numa direção nitidamente oposta -, tendo em vista a necessidade de fundar suas premissas.

9 Hovenkamp (1990) aponta para a tese segundo a qual a teoria econômica preponderante já influenciava profundamente a decisão judicial, como no caso da doutrina do Substantive Due Process, que segundo ele era dominada pela economia política clássica: " [...] the importance of this argument is not to show that judges were right, but that political economy helped them think they were right". 
o direito tinha um papel transformador e que esse papel seria melhor desenvolvido se fosse difundida a sua relação com a economia, entendida como ciência capaz de fortalecer a promoção da redistribuição da riqueza na sociedade.

A desconfiança em relação às possibilidades do livre mercado para desenvolver essa ação transformadora fez com que a compreensão da afinidade entre as disciplinas direito e economia fosse amplamente estimulada pela parte crítica do realismo, isto é, aquela parte radical do movimento cuja visão se direcionava para fora das regras clássicas do common law, e que, por consequência, acreditava numa legislação progressista à implementação do bem estar coletivo. (HOVENKAMP, 1990, p. 995)

Se, por um lado, o aspecto histórico e estatístico veio fortalecido no debate econômico, pelo desencadeamento da força do movimento institucionalista, cuja adequação do método indutivo promovido pela German Historical School foi uma espécie de ruptura paradigmática; por outro, o início da Revolução Marginalista, que cunhou o termo utilidade marginal, foi de grande influência por reformular a teoria do valor.

Sob um outro viés, fora do custo histórico da produção, base da teoria do valor desenvolvida pelos economistas políticos clássicos, o valor de um bem não mais estava relacionado e dependente da quantidade de trabalho a ele empregado previamente, mas sim se vinculava a questões subjetivas, estabelecidas pela utilidade marginal de cada bem, cuja medida era determinada por uma avaliação comportamental, consubstanciada na motivação marginal de pagar. (HOVENKAMP, 2000, p. 817)

Não obstante a forte guinada conservadora da corrente marginalista, determinada especialmente pelo pensamento de Robbins (1938, p. 635) no início da terceira década do século XX, que desvinculou as implicações da teoria neoclássica da ideia de bem-estar social e, assim, de uma análise da comparação individual da utilidade, o projeto inicialmente erguido sobre essa pilastra fez com que se fortificasse, em alguma medida, a proposta cada vez mais intensa de intervenção estatal no mercado ${ }^{10}$.

10 Embora a nítida divergência metodológica entre os neoclássicos que seguiram a esteira de Robbins - e que defendiam equilíbrio a longo prazo, concorrência perfeita, etc. - e a Escola Austríaca de Economia, reconhecida no pensamento de autores como, por exemplo, 
Dito de outro modo, o marginalismo foi uma especificação coerente em se tratando do interesse dos progressistas, para compreender como os incentivos humanos poderiam ser controlados e, especialmente, para delinear como o bem-estar humano poderia ser promovido.

Nesses termos, o sentido dado à intervenção estatal, cuja proposta surge pela aglutinação dos redimensionamentos ocorridos em ambas as disciplinas - direito e economia -, estava voltado à expansão das bases da já iniciada teoria da redistribuição da riqueza, e essa expansão era o nexo fundamental que caracterizava o chamado First Law and Economics Movement. (HOVENKAMP, 1990, p. 1.001)

Assim, teve função importante a escola reconhecida como Material Welfare, capitaneada por Alfred Marshal e Arthur Pigou em Cambridge, na medida em que foi bastante influente entre os pensadores progressistas americanos, mais especificamente aqueles voltados à corrente crítica ou radical do realismo como, por exemplo, Richard Ely e Edwin R. A. Seligman, os quais defendiam que a transferência involuntária de riqueza poderia fazer com que a sociedade, em sentido amplo, se tornasse melhor.

Tendo em vista a equação composta pelos marginalistas, que dimensionava a possibilidade de uma pessoa obter satisfação em relação a um bem de acordo com a sua utilidade marginal, isto é, pelo valor empregado à última unidade de um determinado bem, a política progressista, em direção da maximização do bem-estar social, voltou-se ao conceito de utilidade marginal para indicar que a utilidade social seria maximizada na medida em que fossem igualadas as utilidades marginais individuais.

Assim, uma política de transferimento forçado de riqueza, do rico ao pobre, segundo essa visão do marginalismo promovido pela Material Welfare School, possibilitaria a conclusão de que a utilidade social total mesmo permanecendo inalterado o ganho real agregado da comunidade - se fortaleceria, tendo em vista que os ganhos interpessoais passariam,

von Mises e Friedrich Hayek, é importante ressaltar a influencia desta àqueles, na medida em que Robbins seguiu assiduamente o famoso seminário promovido por Misses na Câmara de Comércio de Viena - privatseminar -, desenvolvido entre as décadas de 1920 e 1930. Talvez tenha surgido em virtude dessas discussões o subjetivismo sustentado por Robbins. (HUERTA DE SOTO, 2005, p. 169-170) 
necessariamente, por um processo de nivelamento das utilidades individuais agregadas.

Noutras palavras, esse conceito de bem-estar explicitou a compreensão de que os acadêmicos envolvidos na evolução da relação entre direito e economia confiavam num alto grau de estatização à implementação de políticas públicas voltadas para, por exemplo, o mínimo salarial, o ensino público gratuito, a taxação gradativa em relação aos lucros, os pagamentos dirigidos aos mínimos vitais dos pobres, etc. Mais: o âmago do pensamento vinha construído pela ideia de que a distribuição igualitária de riqueza seria capaz de promover e fortificar o bem-estar social.

De todo modo, no período da Progressive Era, o debate que ganhou tônus foi aquele referente à objetividade dessas legislações intervencionistas, ou seja, da cientificidade das leis pelas quais o poder público dispunha sobre a redistribuição igualitária de riqueza. Dentre essas leis, as que mais provocaram controvérsias foram aquelas que determinavam, pela crença em critérios empíricos, a base de um mínimo salarial para a população.

Os progressistas, nesse sentido, acreditavam que era possível medir científica e objetivamente a quantidade mínima de recursos necessária para a sobrevivência de uma família. Valendo-se da Teoria da Evolução de Darwin, (DARWIN, 1998) compactuada com a ideia de utilidade marginal, eles elencaram as seguintes questões: a) os seres humanos têm um envolvimento biológico forte e suas preferências são construídas primordialmente levando em consideração o instinto de sobrevivência; b) diferentemente dos outros organismos, os seres humanos são capazes de modificar e dirigir o seu próprio processo evolutivo; c) indivíduos têm necessidades e desejos por bens, porém quanto mais um determinado indivíduo tem de um bem, menos intensamente esse bem influi na vida desse indivíduo; d) o livre mercado é visto como frágil e manipulado pelo poder dominante e não tem o aspecto descrito pela política econômica clássica; e) a homogeneidade entre indivíduos, ditada pelo processo evolucionário, faz com que seja possível a comparação interpessoal das necessidades ao bem-estar; f) o estado tem a capacidade de promover o bem-estar, en- 
volvendo-se no processo de redistribuição de recursos. (HOVENKAMP, 2000, p. 820)

Diante dessas bases, a teoria progressista aglutinou em si, por um lado, a consideração das preferências individuais; por outro, a homogeneidade substancial dessas preferências, as quais eram conduzidas pelo processo evolucionário, isto é, tais preferências não eram nada mais do que o instinto de sobrevivência que cada ser humano carregava consigo, cuja contingência vinha determinada por esse processo.

Assim, o pensamento jurídico progressista tinha uma complexa raiz, que, contudo, não o impossibilitava de apontar para a distribuição mais igualitária da riqueza e para o fortalecimento do bem-estar social: por um lado, quanto aos seus fundamentos à escolha humana, era individualista e liberal; por outro, em se tratando da natureza humana e do bem-estar, era nitidamente coletivista. Isso fazia com que o movimento Law and Economics das primeiras décadas do século XX fosse técnico e formal, por conta dos descobrimentos da utilidade marginal; prático e histórico-material, tendo em vista o desenvolvimento do institucionalismo econômico (VEBLEN, 1899; VEBLEN, 1904; COMMONS, 1925; COMMONS, 1934). Não obstante tudo isso, em se tratando da teoria social pela qual veio construído o pensamento legal progressista, privilegiava-se o republicanismo, em detrimento da ideia liberal clássica. (HOVENKAMP, 2000, p. 810)

De todo modo, institucionalismo e marginalismo, naquele período, tiveram uma relação virtuosa, na medida em que ambos reconheceram, pela ideia progressista de concepção social de valor econômico, a comparação interpessoal da utilidade. Os institucionalistas não rejeitaram o marginalismo como princípio basilar à compreensão da economia, mas sim o criticaram quando a análise marginal foi defendida como explanação completa, restritiva e inexorável do comportamento do mercado.

As fontes clássicas da economia, nesse sentido, foram atingidas por dois ângulos diversos, aglutinados pela crença progressista de que a concepção social do valor econômico encontrava-se implícita no marginalismo, diferentemente da ideia fechada e conservadora de valor dos 
clássicos, calcada unicamente na concepção de custo de produção e sem nenhuma composição social.

A grande resistência do classicismo econômico, todavia, não veio diretamente dos autores voltados à economia em si. Tratando-se da realidade americana, como cadencialmente se vem demonstrando, a resistência positiva à manutenção dos preceitos clássicos do livre mercado vinha diretamente da Suprema Corte Americana, cuja interpretação do 14th Amendment, naquele tempo, defendia que o salário legal era estabelecido diretamente pelas leis do livre mercado.

Aliás, orientando-se sempre em direção da manutenção do status quo, a corte, ainda, empregou em suas decisões posições contrárias à comparação interpessoal da utilidade marginal - aquela desenvolvida pelos progressistas -, e constitucionalizou o critério subjetivo, isto é, a reviravolta dada na compreensão do próprio critério de utilidade marginal à escolha das preferências individuais, não mais direcionado ao bem-estar social, mas unicamente ao lucro, ou, melhor dizendo, à maximização da utilidade composta pela compreensão de bem-estar individual: “[...] liberty of contract represented the judicial triumph of the subjective, individualistic doctrine of welfare over the "social" or objective doctrine." (POUND, 1909, p. 454)

Com o fortalecimento da análise marginal e com a teoria do preço por ela edificada mudando de direção, ou seja, voltando-se à proposta da teoria da organização industrial, em que a premissa do lucro privado como maximização da utilidade tomou o lugar da proposta de redistribuição, o marginalismo econômico neoclássico, redimensionado pela Revolução Ordenalista Subjetivista de 1930, desestruturou a teoria progressivista do bem-estar social, deixando intacta, isto é, revigorando, de todo modo, a teoria dos incentivos individuais.

Depois de 1930, o pensamento marginalista encorajou o desenvolvimento do ator econômico individual e do livre mercado, contudo, não mais se voltou as consequências desse desenvolvimento ao bem-estar coletivo, tampouco ao apoio da política legislativa estatal com fins redistributivos. 
Gradativamente, enquanto a chamada mainstream economics - a teoria econômica dominante - abandonou a crença inicial de desconfiança no mercado, reconstruindo, assim, um modelo teorético capaz de tornar o âmbito econômico privado o grande precursor à alocação de recursos, argumentando, contra as agências regulatórias do Estado, além da existência de interesses especiais por parte dessas, a imperfeição do processo político e a impossibilidade da votação majoritária em produzir resultados estáveis à maximização do bem-estar (COASE, 1960; ARROW, 1950); o pensamento progressista respondeu à altura, abandonando a mainstream economics neoclássica e com ela a sua interpretação prévia de não intervenção do Estado na economia.

Obviamente permanece, em se tratando dos progressistas, para a composição do valor social, a influência dos utilitaristas ingleses e da Escola Histórica Alemã. A sociologia e a psicologia assumiram papel fundamental na teoria jurídica, a economia - mainstream economics - cabalmente perdeu espaço, ficando a periferia do direito.

Em outras palavras, na medida em que a economia neoclássica foi se desenvolvendo, fundando-se em conceitos puros e matemáticos, os progressistas voltaram sua teoria legal ao institucionalismo, que naquele período, por volta da terceira década do século XX, por sua vez, foi praticamente excluído do círculo econômico (HOVENKAMP, 2000, p. 837). A economia do bem-estar, nesse aspecto, tornou-se hostil aos elementos redistributivos propostos por ambos os lados da corrente realista - responsável pela fundação do New Deal; segundo eles - os neoclássicos - política de redistribuição de riqueza somente poderia ser justificada se estivesse em voga o seu ponto de vista político e axiológico, mas nunca fundando-se sob as arestas da ciência econômica propriamente dita. (HICKS, 1939; KALDOR, 1939)

Essa mudança foi prontamente identificada por Veblen (1909, p. 620 e ss.), para quem a economia tinha de, cada vez mais, na retromarcha dos neoclássicos, tornar-se uma ciência social, isto é, era papel da economia compreender os hábitos sociais pelos quais os seres humanos estavam sendo influenciados em suas ações. Não bastava, como queriam os neoclássicos subjetivistas, simplesmente levar em consideração as prefe- 
rências humanas como dadas, mostrava-se necessário, isso sim, pesquisar a respeito das fontes evolucionárias desses hábitos sociais que influenciavam tais preferências.

A rejeição da concepção formulada pela mainstream economics de que os seres humanos seriam atores econômicos com uma seleção estável de preferências gerais pelas quais seria possível alcançar o equilíbrio, fez com que Veblen a identificasse como não evolucionária, formalista, taxonômica e tautológica.

\section{Conclusões}

Nesse sentido, o First Law and Economics Movement acreditava no processo evolucionário das instituições como reflexo da mudança gradativa da sociedade, essa mudança gradativa, porém, vinha identificada e garantida pelo direito, mas com uma peculiaridade: a experimentação legislativa era o âmago desse processo evolucionário; o common law, segundo eles, se mostrava muito indolente como mecanismo de controle social.

Nitidamente, esse movimento entre direito e economia no continente americano nasceu de um aspecto revolucionário sob o ponto de vista científico. Pesquisadores voltados à ciência social em geral, mas, ainda, à política, ao direito e à economia estavam engajados na identificação de fundamentos e de justificações para a explanação da relação dessas disciplinas. Interesse, valor, redistribuição involuntária e seus efeitos tinham a amplitude da interdisciplinaridade e tal amplitude não punha em risco nem o caráter científico das pesquisas, tampouco a caracterização econômica da própria disciplina econômica.

Na verdade, o argumento da não cientificidade do método e do não pertencimento das questões - econômicas - discutidas naquele período à ciência econômica, como fatores determinantes da própria desqualificação da relação entre as disciplinas à compreensão da existência de uma primeira corrente Law and Economics, unicamente caracterizou a forte opção político-ideológica proveniente da University of Chicago - locus inicial da aplicação da microeconomia neoclássica subjetivista ao direito a partir da década de 1960 do século XX -, na medida em que avocou 
para si um conceito restrito de ciência, exponencialmente verdadeiro e imutável, que, se visto sob esse mesmo argumento avocado, consequentemente, também assumiria fortes características à declaração de sua não cientificidade.

\section{Referências}

ACKERMAN, Bruce. Nós, o povo soberano: fundamentos do direito constitucional. Belo Horizonte: Del Rey, 2006.

ARROW, Kenneth J. A Difficulty in the Concept of Social Welfare. The Journal of Political Economy, Chicago (US), v. 58, n. 4, 1950.

BEARD, Charles A. An economic interpretation of the Constitution of the United States. New York: Free Press, 1986.

COASE, Ronald H. The Problem of Social Cost. Journal of Law and Economics, Chicago (US), v. 1, n. 1, October, 1960.

COHEN, Felix. Transcendental Nonsense and the Functional Approach.

Columbia Law Review. Columbia (US), v. 6, n. 35, 1935.

COMMONS, John. Institutional economics. New York: McMillan, 1934.

. Law and Economics. Yale Law Journal, Yale (US), n. 34, February, 1925.

DARWIN, Charles. The origin of species. Oxford - New York: Oxford University Press, 1998.

DUXBURY, Neil. Patterns of American jurisprudence. New York:

Oxford University Press, 1997.

FRIED, Barbara $\mathrm{H}$. The progressive assault on laissez faire: Robert Hale and the first Law and Economics movement. 2. ed. USA: Harvard University Press, 2001.

GILMORE, Grant. Le grandi epoche del diritto americano. Milano: Giufrè, 1991. 
HALE, Robert. Our Equivocal Constitutional Guaranties. Columbia Law Review, Columbia (US), n. 39, 1939.

. Force and the State: A comparison of "Political" and

"Economic" Compulsion. Columbia Law Review, Columbia (US), n. $35,1935$.

. Coercion and Distribution in a supposedly Noncoercive State.

Political Science Quarterly, New York (US), n. 38, 1923.

GREY, Thomas C. Langdell's Orthodoxy. University of Pittsburgh Law Review. Pittsburgh (US), v. 1, n. 45, 1983.

HICKS, John. The Foundations of welfare Economics. The Economic Journal, Wiley (US), December, 1939.

HOLMES JUNIOR, Oliver Wendell. The essential Holmes. Chicago: Chicago University Press, 1992.

HOLMES JUNIOR, Oliver Wendell. The common law. New York: Dover, 1991.

HORWITZ, Morton. The transformation of american law, 1870-1960: the crisis of legal ortodoxy. New York: Oxford University Press, 1992. HOVENKAMP, Herbert. Knowledge About Welfare: Legal Realism and the Separation of Law and Economics. Minnesota Law Review, Minnesota, v. 84, 2000.

. Enterprise and American Law 1836-1937. USA: Harvard University Press, 1991.

. The First Great Law \& Economics Movement. Stanford Law Review, Stanford, n. 42, 1990.

. The Mind and Heart of Progressive Legal Thought. [2011].

Disponível em: <http://sdrc.lib.uiowa.edu/preslectures/hovenkamp95/ hovenkamp1.html >. Acesso em: $1^{\circ}$ mar. 2011.

HUERTA DE SOTO, Jesús. Escola austríaca: mercado e criatividade empresarial. Lisboa: Causa Liberal, 2005. 
KALDOR, Nicholas. Welfare Propositions in Economics and Interpersonal Comparison of Utility. The Economic Journal, Wiley (US), September, 1939.

\section{MACPHPERSON, C. B. The political theory of possessive}

individualism: Hobbes to Locke. 8. ed. Oxford: Oxford University Press, 1979.

MILL, John Stuart. The principles of political economy with some of their applications to social philosophy. School of Economics, Finance and Management - University of Bristol. [2011]. Disponível em: $<$ http:// www.ecn.bris.ac.uk/het/mill/prin.htm>. Acesso em: $1^{\mathrm{o}}$ mar. 2011.

MINDA, Gary. Teorie posmoderne del diritto. Bologna: Mulino, 2001.

NELSON, Willian E. The Fourteenth Amendment: from political principle to Judicial doctrine. USA: Harvard University Press, 1998.

PEIRCE, Charles S. How to Make Our Ideas Clear. Popular Science Monthly, Winter Park (US), n. 12, 1878.

ROBBINS, Lionel. Interpersonal Comparisons of Utility. The Economic Journal, Wiley (US), n. 635, 1938.

POUND, Roscoe. Law in Books and Law in Action. American Law Review, Fresno (US), n. 34, 1910.

. Liberty of Contract. Yale Law Journal, Yale (US), n. 18, 1909. . Mechanical Jurisprudence. Columbia Law Review, Columbia (US), n. 8, 1908.

SPENSER, Herbert. The Man versus The State, with six essays on government, society and freedom. Indianapolis: Liberty Classics, 1981. STRUM, Philippa. Louis Brandeis: justice for the people. Cambridge: Harvard University Press, 1984.

SUPREME COURT OF THE UNITED STATES. Lochner versus New York. 198 U.S. 45, 1905. Disponível em: <http://www.law.cornell.edu/ supct/html/historics/USSC_CR_0198_0045_ZS.html> Acesso em: 7 nov. 2012. 
VEBLEN, Thorstein. The Limitations of Marginal Utility. Journal of Political Economy, Chicago (US) n. 17, 1909.

VEBLEN. Thorstein. The theory of business enterprise. New York: Charles Scribner's Sons, 1904.

VEBLEN. Thorstein. Theory of leisure class. New York: Macmillan, 1899. 